\title{
Investigation of donkey milk bacterial diversity by 165 rDNA high-throughput sequencing on a Cyprus donkey farm
}

\author{
P. Papademas, ${ }^{1 *} \dagger \odot$ E. Kamilari, ${ }^{1 *} \odot$ M. Aspri, ${ }^{1} \odot$ D. A. Anagnostopoulos, ${ }^{1} \odot$ P. Mousikos, ${ }^{1} \odot$ A. Kamilaris, ${ }^{2,3} \odot$ \\ and D. Tsaltas ${ }^{1} \dagger$ (D) \\ ${ }^{1}$ Department of Agricultural Sciences, Biotechnology and Food Science, Cyprus University of Technology, Limassol 3036, Cyprus \\ ${ }^{2}$ Faculty of Electrical Engineering, Mathematics and Computer Science (EEMCS), University of Twente, Enschede, 7522 NB, the Netherlands \\ ${ }^{3}$ Research Centre on Interactive Media, Smart Systems and Emerging Technologies-RISE, Nicosia 1066, Cyprus
}

\section{ABSTRACT}

The interest in milk originating from donkeys is growing worldwide due to its claimed functional and nutritional properties, especially for sensitive population groups, such as infants with cow milk protein allergy. The current study aimed to assess the microbiological quality of donkey milk produced in a donkey farm in Cyprus using culture-based and high-throughput sequencing techniques. The culture-based microbiological analysis showed very low microbial counts, whereas important food-borne pathogens were not detected in any sample. In addition, high-throughput sequencing was applied to characterize the bacterial communities of donkey milk samples. Donkey milk mostly composed of gram-negative Proteobacteria, including Sphingomonas, Pseudomonas, Mesorhizobium, and Acinetobacter; lactic acid bacteria, including Lactobacillus and Streptococcus; the endospores forming Clostridium; and the environmental genera Flavobacterium and Ralstonia, detected in lower relative abundances. The results of the study support existing findings that donkey milk contains mostly gram-negative bacteria. Moreover, it raises questions regarding the contribution of (1) antimicrobial agents (i.e., lysozyme, peptides) in shaping the microbial communities and (2) bacterial microbiota to the functional value of donkey milk.

Key words: donkey milk, 16S rDNA sequencing, highthroughput sequencing, bacterial communities

Received July 7, 2020.

Accepted August 24, 2020.

*These authors contributed equally to this work.

†Corresponding authors: photis.papademas@cut.ac.cy and dimitris. tsaltas@cut.ac.cy

\section{INTRODUCTION}

Milk from nontraditional animal species (i.e., donkey, camel, and buffalo) are recently gaining interest for research and regulatory authorities, mainly because they are considered valuable alternative nutritional sources for specific population groups (i.e., infants, the elderly, immunocompromised, and those allergic to cow milk protein; Jirillo et al., 2010; Salimei and Fantuz, 2012; Aspri et al., 2017a). In particular, the interest in donkey milk has increased dramatically over the past few years due to its nutritional, nutraceutical, functional, and immunological properties (Aspri et al., 2017b). Several studies have demonstrated that donkey milk maintains antimicrobial (Zhang et al., 2008; Brumini et al., 2013; Koutb, 2016; Adduci et al., 2019), antiinflammatory (Jirillo and Magrone, 2014; Yvon et al., 2018), antimitotic, as well as antitumor (Mao et al., 2009) capacities. Furthermore, it has been reported to be a suitable alternative for infants suffering from cow milk protein allergy (Souroullas et al., 2018).

Donkey milk is characterized by a very low microbial population, which can be attributed to the increased concentrations of antimicrobial factors, including lysozyme and lactoferrin (Vincenzetti et al., 2008; Tidona et al., 2011). Lysozyme is an enzyme that catalyzes the hydrolysis of glycosidic bonds between $\mathrm{N}$-acetylmuramic acid and $N$-acetyl-D-glucosamine residues of peptidoglycan, the primary component of the bacterial cell wall (Brumini et al., 2016; Labella et al., 2016). Lactoferrin is a multipurpose glycoprotein with bacteriostatic and bactericidal activities (Jahani et al., 2015). Its antibacterial activity involves binding to LPS of bacterial walls and (1) absorbs iron, which is required for bacterial growth (Ward and Conneely, 2004); (2) prevents binding of important for bacterial pathogenesis compounds to LPS (Ochoa and Cleary, 2009); (3) binds additional substances and compounds, including heparin, DNA, glycosaminoglycans, as well as metal ions such as $\mathrm{Mn}^{3+}$, $\mathrm{Al}^{3+}, \mathrm{Co}^{3+}, \mathrm{Ga}^{3+}, \mathrm{Zn}^{2+}, \mathrm{Cu}^{2+}$, and so on (Khan et al., 
2001); (4) induces apoptosis in cells (Appelmelk et al., 1994); and (5) apolactoferrin (iron-free lactoferrin) damages the external membrane of gram-negative bacteria by enhancing its permeability (Superti et al., 2005). Indeed, the microbiological data of raw donkey milk show a significantly low total bacteria count with a mean population of 2.40 to $5.87 \log \mathrm{cfu} / \mathrm{mL}$ (Coppola et al., 2002; Salimei et al., 2004; Chiavari et al., 2005; Zhang et al., 2008; Malissiova et al., 2016). However, the presence of food-borne pathogens such as Escherichia coli O157, Listeria monocytogenes, Bacillus cereus, and Campylobacter spp., have been detected in some studies (Cavallarin et al., 2015; Colavita et al., 2016; Mottola et al., 2018).

Despite the recognized benefits of donkey milk consumption, the existing microbial consortia, and their possible contribution to the milk's nutritional value, have not been evaluated yet. Although various culture-dependent methodologies have identified the presence of bacteria, including food-borne pathogens, in aseptically collected milk, they do not suffice to provide complete information regarding several additional genera present in low numbers or difficult to be cultured (Quigley et al., 2013a). Recently, the high-throughput sequencing (HTS) technology has been applied for deeper identification of the vastly diverse bacterial communities present in different types of milk (De Filippis et al., 2018; Oikonomou et al., 2020). This technology provides the ability to characterize the microbiota present within a sample comprehensively, and it is characterized by increased sensitivity and high throughputness in comparison to other culture-independent methodologies. Amplicon sequencing achieves this by generating and sequencing in parallel thousands of specific DNA sequences, such as the bacterial 16S rDNA gene (Bokulich and Mills, 2013). The microbiome of donkey milk is hypothesized to be composed of bacteria commonly found in milk samples, but with adaptation to the elevated presence of antimicrobial compounds. Previous HTS studies on donkey milk bacterial communities identified increased relative representation of gram-negative bacteria, such as Pseudomonas spp. (Soto Del Rio et al., 2017; Russo et al., 2020).

Therefore, considering the growing interest in donkey milk for infants, adults, and elderly, the study aims to identify and characterize the bacterial communities of donkey milk produced in a donkey farm in Cyprus, as well as to evaluate its microbiological quality by using culture-based approaches in combination with Illumina MiSeq (Illumina, San Diego, CA) amplicon sequencing. The extracted findings are expected to increase knowledge regarding the bacterial consortium comprising the donkey milk and provide indications of the key bacterial microbiome that contributes to donkey milk's elevated nutritional value.

\section{MATERIALS AND METHODS}

\section{Collection of Milk Samples}

Milk samples were collected from the Golden Donkeys Farm, located in Larnaca District, Cyprus. All donkeys were fed on the same diet consisting of hay, barley, corn, and a concentrate of minerals, vitamins, and salt following the European Directive 98/58/EC (European Union, 1998). Donkeys were healthy and no antibiotics were administered before sampling. Milking was carried out in the stable and donkeys were milked manually from the same milker, adhering to strict personal hygiene conditions, once daily during the morning. Milk was immediately transferred to refrigeration $\left(6^{\circ} \mathrm{C}\right)$ until further processing (same day).

Sampling for chemical and microbiological analysis was conducted weekly (33 wk) from October of 2018 to May 2019 from the daily milk batch (20 L from 20 to 25 milking donkeys). Milk samples for $16 \mathrm{~S}$ rRNA gene amplicon analysis was conducted in May 2019 from 11 donkeys. For chemical and microbiological analysis from each donkey, a total of $250 \mathrm{~mL}$ of milk from both mammary glands were collected into a $250-\mathrm{mL}$ sterile container. For $16 \mathrm{~S}$ rRNA gene amplicon analysis a total of $100 \mathrm{~mL}$ of milk from both mammary glands was collected into two 50-mL sterile tubes (2 samples/donkey). During milking, the udder was cleaned using sterile wet wipes and the nipples using $70 \%$ ethanol and dried with sterile gauze. The donkeys were all multiparous. Donkey milk samples were placed in cool-boxes and immediately transported to the laboratory, where (1) they were kept at $4^{\circ} \mathrm{C}$ and processed during the same working day for chemical and microbiological culturebased analysis, or (2) stored at $-80^{\circ} \mathrm{C}$ for $16 \mathrm{~S}$ rRNA gene amplicon-HTS analysis.

\section{Chemical Analysis and Lysozyme Activity}

Chemical analyses of fresh raw donkey milk were performed by using standard methods [i.e., total nitrogen content (ISO 8968-1:2014, ISO, 2014), fat (ISO 488:2008, ISO, 2008), and TS (ISO 6731:2010, ISO, 2010)]. All the analyses were done in triplicates, and average values were reported. Lysozyme concentration was quantified using an ELISA kit (Human Lysozyme ELISA KIT ab108880; Abcam, Cambridge, UK). The test was performed according to the manufacturer's instructions and the absorbance was determined spectrophotometrically (Infinite PRO 200, Tecan, Switzer- 
Table 1. Methods used for the enumeration of microorganisms

\begin{tabular}{|c|c|c|c|}
\hline Group of microorganisms & Growth medium $^{1}$ & Incubation conditions & Reference method \\
\hline Enterobacteriaceae & VRBGA (Oxoid, Basingstoke, UK) & $37^{\circ} \mathrm{C}, 24 \mathrm{~h}$ & ISO $21528-2: 2017^{3}$ \\
\hline Staphylococci & BP (Oxoid) & $37^{\circ} \mathrm{C}, 48 \mathrm{~h}$ & ISO $6888-1: 1999^{4}$ \\
\hline Escherichia coli & TBX (Oxoid) & $44^{\circ} \mathrm{C}, 24 \mathrm{~h}$ & ISO $16649-2: 2001^{6}$ \\
\hline Listeria monocytogenes & ALOA (Oxoid) & $37^{\circ} \mathrm{C}, 48 \mathrm{~h}$ & ISO $11290-1: 2017^{7}$ \\
\hline
\end{tabular}

${ }^{1} \mathrm{PCA}=$ plate count agar; VRBGA = violet red bile glucose agar; $\mathrm{BP}=$ Baird Parker; $\mathrm{MYP}=$ mannitol egg yolk polymixin; TBX = tryptone bile x-glucuronide; ALOA = Listeria chromogenic agar base acc. to Ottaviani and Agosti.

${ }^{2} \mathrm{ISO}, 2013$.

${ }^{3} \mathrm{ISO}, 2004 \mathrm{a}$.

${ }^{4} \mathrm{ISO}, 1999$.

${ }^{5} \mathrm{ISO}, 2004 \mathrm{~b}$.

${ }^{6} \mathrm{ISO}, 2001$.

${ }^{7} \mathrm{ISO}, 2017$.

land), at 450 and $570 \mathrm{~nm}$. All samples were analyzed in triplicate.

\section{Microbiological Analysis}

All samples were evaluated for total aerobic bacteria, Enterobacteriaceae, staphylococci, Escherichia coli, and Bacillus cereus after serial dilutions in saline solution $(0.85 \% \mathrm{wt} / \mathrm{vol})$, using pour or spread plate technique. Table 1 shows the growth media, incubation time, temperature, and specific method used for each group of microorganisms inspected. Listeria monocytogenes analysis performed by using ISO method 11290-1:2017 (ISO, 2017). All the analyses were done in triplicate.

\section{S rRNA Gene DNA Isolation}

Five milliliters of donkey milk was mixed with $45 \mathrm{~mL}$ of $2 \%$ tri-sodium citrate (Honeywell, Charlotte, NC). After centrifugation at $16,000 \times g$ for $5 \mathrm{~min}$ at $4^{\circ} \mathrm{C}$, the top fat layer was removed using sterile cotton swabs, based on the manufacturer's instructions for the MoBio Microbial Kit (MoBio Laboratories Inc., Carlsbad, CA; https://www.selectscience.net/products/powerfood -microbial-dna-isolation-kit/?prodID=85256). The isolated DNA was kept at $-20^{\circ} \mathrm{C}$ until processing.

\section{Quantification of Total DNA}

The total DNA extracted from the donkey milk samples was quantified fluorometrically using Qubit 4.0 fluorometer (Invitrogen, Carlsbad, CA) and Qubit dsDNA HS Assay Kit (Invitrogen). Evaluation of DNA purity achieved by measuring the ratios of absorbance A260/280 nm and A260/230 nm, using a spectro- photometer (NanoDrop, Thermo Fisher Scientific, Waltham, MA).

\section{Barcoded Illumina MiSeq Amplicon Sequencing of Bacterial 16S rRNA Gene}

A HTS approach was applied to isolated donkey milk DNA for the identification of the existing bacterial communities. The bacterial V3-V4 hypervariable region of the $16 \mathrm{~S}$ rDNA gene was amplified with the following $16 \mathrm{~S}$ rDNA gene amplicon PCR primer pairs: (1) forward primer (CCTACGGGNGGCWGCAG) and (2) reverse primer (GACTACHVGGGTATCTAATCC), with the overhang adapter sequence addition. The paired-end approach based on the Illumina's protocol was applied (https://support.illumina.com/ documents/documentation/chemistry_documentation/ 16s/16s-metagenomic-library-prep-guide-15044223-b .pdf) and as described by Kamilari et al. (2020). The quantification of each $\mathrm{PCR}$ product DNA concentration was performed using Qubit dsDNA High sensitivity assay. The estimation of DNA quality was evaluated using a bioanalyzer (Agilent 2200 TapeStation, Santa Clara, CA; expected size $\sim 550 \mathrm{bp}$ ). The purification of each PCR amplicon was performed using NucleoMag NGS Clean-up and Size Select (Macherey-Nagel, Düren, Germany). Total amplicon products were normalized in equal concentrations and mixed in a single tube. The MiSeq 300 cycle Reagent Kit v2 (Illumina; $5 \%$ PhiX) was applied for the sequencing runs, whereas the sequencing reaction was performed on a MiSeq Illumina sequencing platform.

\section{Bacterial Microbiome and Statistical Analysis}

The FASTQ sequences were analyzed using Qiime 2 version 2020.2 (Bolyen et al., 2019). For quality filter- 
ing of raw reads, the Phred33 quality threshold was applied. Adapter sequence removal, FASTQ trimming, and read quality control performed using Trimmomatic (Bolger et al., 2014). Additionally, the DADA2 algorithm (Callahan et al., 2016) performed correction of Illumina-sequenced amplicon errors, discarding reads with undesired quality and with more than 2 expected errors, as well as removing chimeric sequences. Sequences were aligned using Mafft (via q2-alignment; Katoh and Standley, 2013). Alpha rarefaction analysis, $\alpha$ diversity metrics (Faith's phylogenetic diversity, Shannon, inverse Simpson, and Chao1), and $\beta$ diversity index (Bray-Curtis similarity) were evaluated via the Qiime2 (version 2020.2) and primer e v7 (https://www .primer-e.com). Principal coordinate analysis was estimated using q2-diversity after 11 samples were rarefied (subsampled without replacement) to 77,143 sequences per sample. Alpha rarefaction curve was plotted with 25 sampling depths. The clustering of the $16 \mathrm{~S}$ rDNA sequences and the filtering in operational taxonomic units (OTU) was performed using 16S Metagenomics App from BaseSpace against the Illumina-curated version of GreenGenes (v.05.2013; DeSantis et al., 2006; Klindworth et al., 2013). The classified OTU were defined at $\geq 97 \%$ of sequence homology and converted to percentages (relative abundances), to determine the representation of each microbe among treatments. The OTU with relative abundance lower than $0.001 \%$ were excluded.

All raw sequence data in read-pairs format were deposited to the National Centre for Biotechnology Information in the Sequence Read Archive under BioProject PRJNA612663.

\section{RESULTS}

\section{Chemical Analysis}

The chemical characteristics of fresh raw donkey milk were evaluated for the period of October 2018 to May 2019, and results are presented in Table 2. Raw donkey milk was characterized by a mean protein content around $1.62 \mathrm{~g} / 100 \mathrm{~mL}$ and a mean fat content of 0.84 $\mathrm{g} / 100 \mathrm{~mL}$. The mean DM observed in the current don-
Table 2. Chemical analysis of donkey milk samples $(\mathrm{n}=33)$

\begin{tabular}{lcccc}
\hline $\begin{array}{l}\text { Constituent } \\
(\mathrm{g} / 100 \mathrm{~mL})\end{array}$ & Minimum & Maximum & Mean & $\mathrm{SD}$ \\
\hline Fat & 0.30 & 1.40 & 0.84 & 0.07 \\
Protein & 1.30 & 1.96 & 1.62 & 0.05 \\
TS & 7.29 & 10.59 & 9.23 & 0.69 \\
\hline
\end{tabular}

key milk study was $9.23 \mathrm{~g} / 100 \mathrm{~mL}$. The mean lysozyme concentration was $2.9 \pm 0.9 \mathrm{mg} / \mathrm{mL}$.

\section{Culture-Based Microbiological Analysis}

Table 3 presents the microbiological results of the 33 raw donkey milk samples for total viable microorganisms, staphylococci, Enterobacteriaceae, Escherichia coli, Bacillus cereus, and Listeria monocytogenes. The mean value of viable microorganisms was $3.80 \log _{10} \mathrm{cfu} /$ mL. Furthermore, staphylococci and Enterobacteriaceae were less than 4.7 and $3.4 \log _{10} \mathrm{cfu} / \mathrm{mL}$, respectively, whereas Escherichia coli, Bacillus cereus, and Listeria monocytogenes were not detected.

\section{S rRNA Gene Amplicon-HTS Analysis}

Abundance and Diversity of Members of the Bacterial Microbiota. Eleven examined sample sets were used as input to the Illumina MiSeq to generate 281,294 high-quality sequencing reads, with an average of $25,572.18$ sequencing reads per sample (range $=$ $17,413-35,159, \mathrm{SD}=5,454.01$ ) at the genus level (Table 4). High-quality sequences were grouped into average number 357.91 OTU (range $=266-492, \mathrm{SD}=66.35$ ). Shannon, inverse Simpson, Chao1, and Chao2 estimators for genus level are also shown in Table 4.

Moreover, to evaluate differences in the bacterial community compositions of donkey milk samples, weighted UniFrac distance-based microbiota structure analysis was performed. Bray-Curtis similarity index indicated increased similarity among the bacterial communities of milk samples at genus level (Supplemental Table S1, https://doi.org/10.3168/jds.2020-19242). Principal coordinate analysis of Bray-Curtis distance indicated no effective discrimination between samples (Figure 1).

Table 3. Microbiological quality of donkey milk samples $(\mathrm{n}=33)^{1}$

\begin{tabular}{lcccc}
\hline Group of microorganisms & Minimum & Maximum & Mean & SD \\
\hline TVC $(\log$ cfu/mL) & 2.90 & 5.10 & 3.80 & 0.02 \\
Enterobacteriaceae $(\log \mathrm{cfu} / \mathrm{mL})$ & $<1.00$ & 3.40 & 1.90 & 0.04 \\
Staphylococci $(\log \mathrm{cfu} / \mathrm{mL})$ & $<1.00$ & 4.70 & 3.10 & 0.06 \\
Escherichia coli $(\log \mathrm{cfu} / \mathrm{mL})$ & $<1.00$ & $<1.00$ & $<1.00$ & $<1.00$ \\
Bacillus cereus $(\log \mathrm{cfu} / \mathrm{mL})$ & $<1.00$ & $<1.00$ & $<1.00$ & $<1.00$ \\
Listeria monocytogenes & $\mathrm{ND}$ & $\mathrm{ND}$ & $\mathrm{ND}$ & $\mathrm{ND}$ \\
\hline
\end{tabular}

${ }^{1} \mathrm{TVC}=$ total viable count; $\mathrm{ND}=$ not detected. 
Papademas et al.: DONKEY MILK MICROBIOME INVESTIGATION

Table 4. Sample information, microbial diversity, and sequence abundance in genus level ${ }^{1}$

\begin{tabular}{lccccccc}
\hline $\begin{array}{l}\text { Sample } \\
\text { ID }\end{array}$ & $\begin{array}{c}\text { Number } \\
\text { of reads }\end{array}$ & $\begin{array}{c}\text { Raw } \\
\text { reads }\end{array}$ & Shannon & Simpson & Chao1 & Chao2 & $\begin{array}{c}\text { Observed } \\
\text { OTU }\end{array}$ \\
\hline D1 & 27,133 & 37,262 & 1.785 & 0.6832 & 472.61 & 263 & 266 \\
D2 & 33,039 & 45,823 & 1.901 & 0.7308 & 636.81 & 632.96 & 328 \\
D3 & 24,904 & 27,634 & 2.097 & 0.7295 & 742.94 & 791.39 & 313 \\
D4 & 26,371 & 37,068 & 1.906 & 0.7289 & 873.48 & $1,005.4$ & 305 \\
D5 & 18,898 & 28,157 & 2.118 & 0.7521 & 938.9 & $1,023.9$ & 312 \\
D6 & 17,413 & 24,025 & 2.961 & 0.8594 & $1,065.1$ & $1,218.2$ & 358 \\
D7 & 24,809 & 34,292 & 2.218 & 0.7353 & $1,177.9$ & $1,310.4$ & 408 \\
D8 & 35,159 & 49,388 & 2.186 & 0.7795 & 1,206 & $1,290.8$ & 410 \\
D9 & 27,872 & 38,799 & 3.368 & 0.9247 & $1,236.5$ & $1,330.6$ & 492 \\
D10 & 20,160 & 28,157 & 2.358 & 0.7534 & 1,255 & $1,393.2$ & 418 \\
D11 & 25,536 & 35,190 & 2.199 & 0.7741 & 1,273 & $1,383.2$ & 327 \\
\hline
\end{tabular}

${ }^{1} \mathrm{OTU}=$ operational taxonomic units.

The principal coordinates 1,2 , and 3 explained $62.24 \%$, $10.30 \%$, and $6.8 \%$ of the variation, respectively. The OTU network showed relation with changes in the microbial population and one main cluster was observed, from which the samples D6, D9, and D10 were discriminated.

Taxonomic Composition of Bacterial Communities in Donkey Milk Samples. According to $16 \mathrm{~S}$ rDNA sequencing, the bacterial communities of donkey milk consisted of mostly members of the phylum Proteobacteria. Members of the phyla Firmicutes, along with Bacteroidetes, Actinobacteria, Acidobacteria, Cyanobacteria, and Verrucomicrobia, were detected in lower relative abundances. Figure 2 illustrates the bacterial composition of the donkey milk samples based on the percentage of sequence reads identified at the genus levels. The most commonly detected bacteria, identified in percentages greater than $1 \%$ in all analyzed samples, were the gram-negative bacteria Sphingomonas

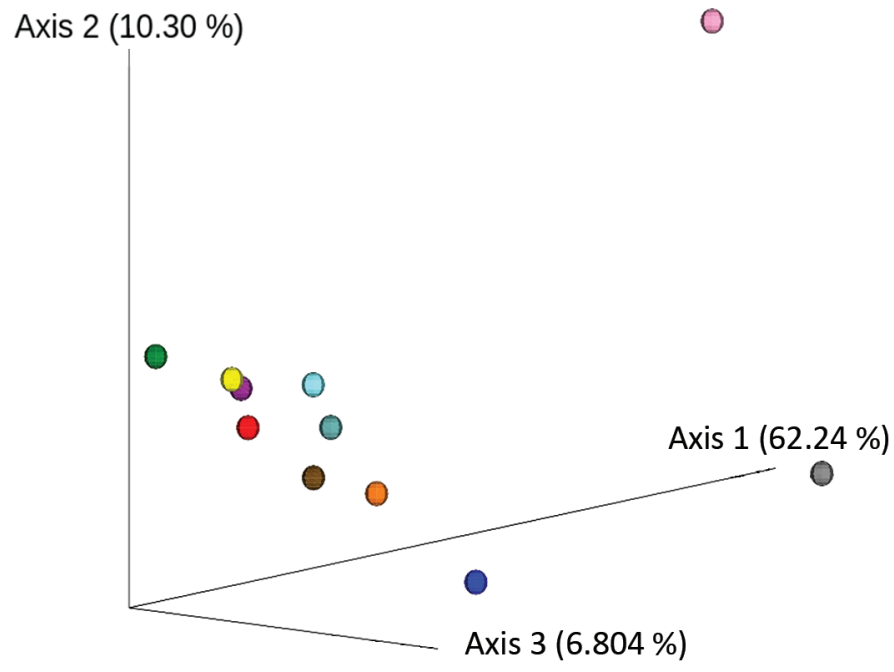

Figure 1. Principal coordinate analysis of donkey milk samples by plots of Bray-Curtis distance. Clustering of points means similarity in relative abundances of operational taxonomic units among those samples.
(16-47\%), Pseudomonas (8-17\%), and Mesorhizobium (11-25\%), as well as the genus Acinetobacter, which was detected in increased relative abundances in 2 samples (samples G3 and G6: 24\% and 16\%, respectively). Moreover, Lactic acid bacteria (LAB), including the genera Lactobacillus and Streptococcus, were detected in relative abundances ranging from $1 \%$ to $4 \%$ in all samples tested. Additional commonly detected genera, but in reduced relative abundance, included the genera Ralstonia ( $0.02 \%$ to $2.6 \%$ ), Aquabacter (0 to $5 \%$ ), and its phylogenetically related Xanthobacter ( $0 \%$ to $5.5 \%$ ), as well as the proteolytic Flavobacterium (0 to 5\%). Furthermore, the number of reads representing $0.1 \%$ to $2 \%$ of the total reads per sample of the spore-forming, butyrate-producing Clostridium was also present.

\section{DISCUSSION}

The current study is the first report in which HTS technology applied to investigate the bacterial communities of Cyprus donkey milk. The $16 \mathrm{~S}$ rRNA gene amplicon-HTS was used for an in-depth quantitative description of the bacterial population structure. Due to new information arising in recent years on the beneficial role of donkey milk consumption, such facilities are on the rise and milk production from other milkproducing species is becoming a niche product.

The results of the chemical composition of donkey milk samples are in line with other studies (Guo et al., 2007; Salimei and Fantuz, 2012; Malissiova et al., 2016). The low content of donkey milk in fat is the main limitation for its use as the sole milk to children allergic to cow milk protein during their first year of life since recommended dietary targets may not be achieved unless adequately supplemented with medium-chain triglycerides (D'Auria et al., 2011; Salimei and Fantuz, 2012).

The microbiological quality of donkey milk using culture-based methods was in accordance with previ- 


\section{Bacterial genera relative abundance}

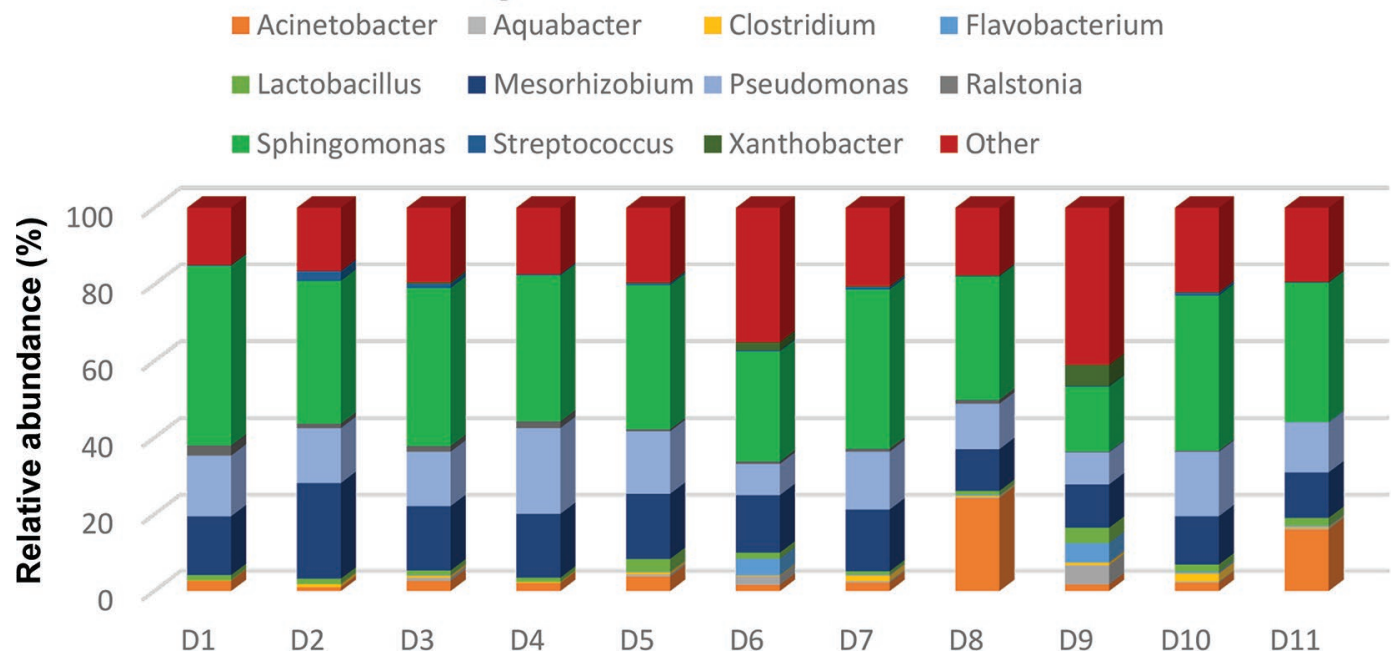

Figure 2. Three-dimensional $100 \%$ stacked column chart of the relative abundance of the major taxonomic groups detected by highthroughput sequencing at genus levels for 11 donkey milk samples, D1 to D11. Only operational taxonomic units with an incidence above $1 \%$ in at least 2 samples are shown.

ous studies (Conte et al., 2005, 2012; Pilla et al., 2010; Sarno et al., 2012; Cavallarin et al., 2015; Malissiova et al., 2016; Mottola et al., 2018). In most studies, including this one, low bacteria counts have been observed. Moreover, only a few studies have shown the presence of some food-borne pathogens, but in the present study, no food-borne pathogens were detected. Furthermore, the low total population of viable microorganisms complies with the EC Regulation 853/2004 (European Union, 2004), allowing the sale of donkey milk under the clause "other milk-producing species," where the total bacterial plate count is less than 1,500,000 cfu/ $\mathrm{mL}$ at $30^{\circ} \mathrm{C}$. Noteworthy, if raw milk from species other than cows is intended for the manufacture of products made with raw milk by a process that does not involve any heat treatment, food business operators must take steps to ensure that the raw milk used meets the following criterion: plate count at $30^{\circ} \mathrm{C}$ (per $\left.\mathrm{mL}\right) \leq 500,000$ (EC Regulation 853/2004; European Union, 2004). The high content of donkey milk in antimicrobial proteins, including lysozyme and lactoferrin, in combination with lactoperoxidase and immunoglobulins, are considered responsible for the low total bacterial counts (Salimei et al., 2004; Vincenzetti et al., 2008; Šarić et al., 2012; Cosentino et al., 2016).

The OTU analysis of the $16 \mathrm{~S}$ rDNA gene sequences indicated that the gram-negative bacteria Sphingomonas, Mesorhizobium, and Pseudomonas were the most dominant genera detected in the Cyprus donkey milk samples. Other genera commonly occurred include Acinetobacter, Lactobacillus, Streptococcus, Ralstonia, Clostridium, and Flavobacterium. Previous metage- nomic studies in donkey milk microbiota have also detected the presence of these genera, except Clostridium, but in different relative abundances (Table 5; Soto Del Rio et al., 2017; Russo et al., 2020). Soto Del Rio et al. (2017) indicated that the predominant genera were Pseudomonas, Ralstonia, Sphingobacterium, Acinetobacter, Cupriavidus, and Citrobacter, although the core bacterial representation differed among samples. This is probably because the samples obtained from 5 different donkey dairy farms during $2 \mathrm{yr}$, in contrast to the current study in which samples were obtained from one farm, during a shorter period. In agreement, Russo et al. (2020) identified also increased relative representation of the genus Pseudomonas in fresh donkey milk samples. Additional genera that detected in lower relative abundances included Chryseobacterium, Sphingobacterium, Stenotrophomonas, Citrobacter, and Delftia. Similar 16S rDNA sequencing analyses in human and bovine milk also identified the frequent presence of the genera Ralstonia, Sphingomonas, and Pseudomonas in all samples tested (Hunt et al., 2011; Kuehn et al., 2013).

The high abundance of gram-negative compared with gram-positive bacteria could be due to the presence of lysozyme. The mean value of lysozyme concentration of donkey milk used in this study was $2.9 \pm 0.9 \mathrm{mg} /$ $\mathrm{mL}$, which is in accordance to literature and is higher than the lysozyme concentration of bovine $(0.09 \mathrm{mg} / \mathrm{L})$ and human $(200 \mathrm{mg} / \mathrm{L}$ ) milk (Chiavari et al., 2005; Vincenzetti et al., 2008). The mean value of lysozyme concentration ranges from 1 up to $4 \mathrm{mg} / \mathrm{mL}$ among the different donkey breeds. Its hydrolytic activity against 
Table 5. The relative representation of bacterial genera that detected in milk samples via 16S rDNA sequencing

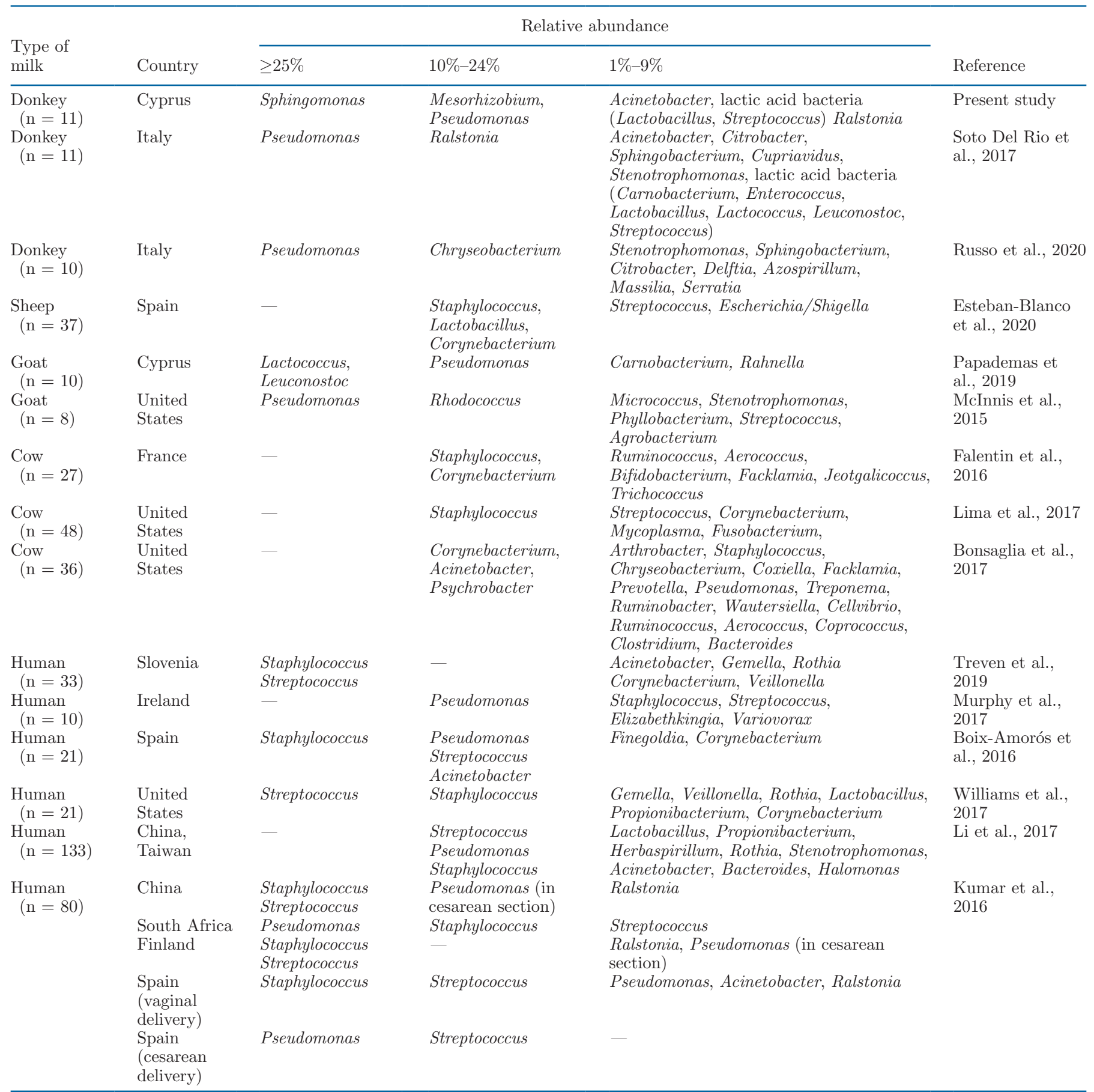

the glycosidic bonds of peptidoglycan makes lysozyme more effective against gram-positive bacteria. Indeed, recent $16 \mathrm{~S}$ rDNA metagenomic studies that performed in other animals' milk with a lower concentration of lysozyme, including goat, sheep, cow, and human, indicated the presence of gram-positive bacteria such as Staphylococcus and Streptococcus, in high percentages (Table 5; Oikonomou et al., 2020) reported that
Staphylococcus and Streptococcus were among the most commonly detected genera between human and cow milk, in addition to Corynebacterium, Pseudomonas, Bacteroides Bifidobacterium, Propionibacterium, and Enterococcus. Apart from lysozyme, a second antimicrobial agent that is present in donkey milk is lactoferrin. Lactoferrin is detected in lower concentration compared with lysozyme (up to $135 \mu \mathrm{g} / \mathrm{mL}$; Papade- 
mas et al., 2019). These 2 proteins were reported to act synergistically against gram-negative bacteria also (Ellison and Giehl, 1991; Hunt et al., 2011). The capacity of lactoferrin to bind LPS of gram-negative bacteria may provide access to lysozyme's molecules to target and degrade the peptidoglycan in the cell wall. Based on the current findings, though, lactoferrin's presence in limited concentrations might not suffice to prevent the growth of gram-negative bacteria.

The most abundant genus in all donkey milk samples was Sphingomonas. This genus is characterized by the presence of glycosphingolipids instead of LPS in their cell envelopes. Also, they possess the ability to grow in stressful for most bacteria environments (Nishiyama et al., 1992; Krziwon et al., 1995; Kelley et al., 2004). They are considered spoilage bacteria in raw milk, in addition to Acinetobacter and spore-forming Clostridia (Zhang et al., 2019). However, spoilage of milk has mostly been attributed to the psychrotrophic members of the genus Pseudomonas. Pseudomonas was detected in increased relative abundances in several milk samples. The capability of Pseudomonas spp. to successfully utilize milk proteins and lipids due to their proteolytic and lipolytic enzymatic activities provides them with the ability to grow in raw milk (Quigley et al., 2013a; Porcellato et al., 2018). Pseudomonas spp. are considered to be among the species responsible for limiting donkey milk's shelf-life (approximately $3 \mathrm{~d}$; Soto Del Rio et al., 2017).

The genus Mesorhizobium comprises soil bacteria that colonize legume roots and assist in the transformation of atmospheric nitrogen into plant-available compounds (Lindström et al., 2010). Forage legumes are important sources of protein, fiber, and energy for animal-based agriculture. Moreover, legume grazing supports meat and milk production, as well as suppressed growth of internal parasites that provoke animals' mortality (Karaś et al., 2015). Detection of Mesorhizobium was also reported in another donkey milk metagenomic study (Soto Del Rio et al., 2017) but in lower relative abundances. Additional nitrogen-fixing bacteria detected, but in limited relative abundances $(<1 \%)$, include Rhizobium, Azorhizobium, Sinorhizobium/Ensifer, Azospirillum, and Nitrospirillum. The occurrence of these symbiotic bacteria might be associated with donkeys' nutrition, and specifically with legumes (Aganga et al., 2000). Legumes are an essential source of donkeys' necessary AA because donkeys cannot store them efficiently. Rodriguez (2014), working with human milk, suggested that selected bacteria of the maternal gastrointestinal microbiota can access the mammary glands through oromammary and enteromammary pathways. The mechanism involves dendritic cells and CD18 cells, which would be able to take up nonpathogenic bacteria from the gut epithelia cells and subsequently, to carry them to other locations, including the lactating mammary gland.

The presence of LAB, including Lactobacillus and Streptococcus, was indicated in all donkey milk samples, with average relative abundance of $2.42 \%$ (ranging from $1 \%$ to $4 \%$ ). These results are in agreement with the other 16S rRNA gene amplicon-HTS studies of Soto Del Rio et al. (2017) and Russo et al. (2020) on donkey milk microbiota, in which the average relative abundances of $\mathrm{LAB}$ were $4.2 \%$ and $2.55 \%$, respectively. The LAB are commonly detected in milk and dairy samples due to their capacity to ferment lactose successfully (Quigley et al., 2013b; Kamilari et al., 2019). Furthermore, the present of coccus-shaped bacteria such as Streptococcus may also be due to the high lysozyme content in donkey milk. According to Neviani et al. (1991) LAB cocci are more resistant to lysozyme than lactobacilli, and among lactobacilli, the lysozyme sensitivity is species or strain-specific; for instance, thermophilic species are more sensitive than hetero-fermentative mesophilic lactobacilli. The LAB possess antimicrobial properties, mainly due to the presence of bacteriocin-like inhibitory substances (Macaluso et al., 2016). In a study carried out by Aspri et al. (2017c), it was shown that the main LAB isolated from donkey milk samples belong to the Enterococcus species. Most of the isolates had interesting technological properties and were able to produce bacteriocins, whereas no pathogenicity was detected. Their presence in milk restricts the risk of food-borne diseases caused by bacteria, including Staphylococcus aureus, Listeria monocytogenes, pathogenic Escherichia coli, and Salmonella spp. (Arqués et al., 2015), and increases milk safety for consumers.

In the present study, the application of culture-based approaches identified the presence of staphylococci and Enterobacteriaceae in less than 4.7 and $3.4 \log _{10} \mathrm{cfu} /$ $\mathrm{mL}$, respectively. The $16 \mathrm{~S}$ rDNA sequencing analysis detected number of reads belonging to the genus Staphylococcus and the family Enterobacteriaceae that corresponded to low relative abundances $(0.034 \%$ to $0.188 \%$ and $0.152 \%$ to $2.375 \%$, respectively). Moreover, the culture-based analysis indicated the absence of the species Escherichia coli, Bacillus cereus, and Listeria monocytogenes. Regarding Escherichia coli and Listeria monocytogenes, culture-based results were in agreement with $16 \mathrm{~S}$ rDNA metagenomic analysis findings. However, some reads corresponding to the genus Escherichia/ Shigella were identified (5-52 reads) but assigned to the species Escherichia/Shigella dysenteriae and Escherichia vulneris. Also, HTS identified the presence of Bacillus cereus in 2 species, but in limited relative representation $(0.02 \%)$. Based on these observations, $16 \mathrm{~S}$ rRNA gene sequencing analysis showed higher 
sensitivity to detect specific bacteria than the usual culture-based method.

The present study indicated that donkey milk harbors complex bacterial communities containing different microorganisms. Still, the identification of the origin of the milk microbiota remains largely unknown. In agreement with other studies on donkey milk microbiome (Soto Del Rio et al., 2017; Russo et al., 2020), the plethora of the detected bacteria are considered environmental. Their existence in donkey milk might come from external contamination of the breast (or udder) during nursing, derived from the mother's skin or the infant's oral cavity. This suggestion is supported by observations on human and bovine milk microbiota, in which species found in the teat skin (Doyle et al., 2016) or the oral cavity (Cabrera-Rubio et al., 2012; Murphy et al., 2017; Williams et al., 2019) were detected in milk. In addition, some researchers suggest an endogenous origin of the milk microbiome, proposing the presence of a hypothetical enteromammary pathway (Jost et al., 2015; Addis et al., 2016; Williams et al., 2019). Interestingly, in the present, as well as other studies on milk microbiota (see Table 5), the detection of LAB, such as Lactobacillus in milk, which contains species associated with the gut microbiome and not detected on the breast skin of humans and animals, supports this theory. Moreover, the presence of alive bacteria in the mammary gland of women who were not breastfed before, indicates also that this tissue might not be sterile (Urbaniak et al., 2014). Noteworthy, bacteria associated with the animal's nutrition, such as Mesorhizobium, were also found in the present study; their origin though remains unspecified. Overall, more effort needs to be provided to specify whether the rich diversity of microbes detected in donkey milk is shaped due to the contamination of the environment or affected by the animals' nutrition and the microbial communities existing in the animals' gut.

\section{CONCLUSIONS}

This is the first study performed to characterize the bacterial communities of donkey milk in a Cyprus farm via HTS. It highlights and confirms that the donkey milk bacterial microbiome is mostly comprised of gram-negative bacteria, possibly due to the increased concentration of lysozyme. In the future, additional donkey milk samples are to be analyzed to enable a broader evaluation and characterization of the existing bacterial communities. Factors that contribute to the conformation of donkey milk microbiota, such as the origin of milk, the environment, animals' health, diet, and genetics, will also be analyzed. The metagenomic analysis could be combined with other methodologies, including proteomics and metabolomics, for a sufficient estimation of the associations among the existing bacteria, the secreted metabolites and the antimicrobial agents detected in donkey milk. These analyses will shed more light on the nutritional benefit and antimicrobial activity of donkey milk.

\section{ACKNOWLEDGMENTS}

The authors acknowledge the technical support and welcoming environment from Golden Donkeys Farm, Cyprus, for the milk samples collection. Author contributions: conceptualization, D.T. and P.P.; methodology, E.K., D.A., and M.A.; formal analysis, E.K., M.A., and A.K.; investigation, E.K., D.A. and M.A.; resources, D.T., P.P., and P.M.; data curation, E.K.; writingoriginal draft preparation, E.K. and M.A.; writingreview and editing, E.K., D.T., and P.P.; supervision, D.T. and P.P.; project administration, D.T.; funding acquisition, D.T. All authors have read and agreed to the published version of the manuscript. Funding: this research was funded by INTERREG Greece-Cyprus 2014-2020 Program [Project AGRO-ID, which is cofunded by the European Union (ERDF) and National Resources of Greece and Cyprus] and project DELIVER by the Research and Innovation Foundation (RIF) of Cyprus. Andreas Kamilaris has received funding from the European Union's Horizon 2020 Research and Innovation Programme under grant agreement No. 739578 complemented by the government of the Republic of Cyprus through the Directorate General for European Programmes, Coordination and Development. The authors declare no conflict of interest.

\section{REFERENCES}

Addis, M. F., A. Tanca, S. Uzzau, G. Oikonomou, R. C. Bicalho, and P. Moroni. 2016. The bovine milk microbiota: Insights and perspectives from -omics studies. Mol. Biosyst. 12:2359-2372. https:/ /doi.org/10.1039/C6MB00217J.

Adduci, F., H. S. Elshafie, C. Labella, M. Musto, P. Freschi, R. Paolino, M. Ragni, and C. Cosentino. 2019. Abatement of the clostridial load in the teats of lactating cows with lysozyme derived from donkey milk. J. Dairy Sci. 102:6750-6755. https://doi.org/10 .3168/jds.2019-16311.

Aganga, A. A., M. Letso, and A. O. Aganga. 2000. Feeding donkeys. Livest. Res. Rural Dev. 12:1-8. https://doi.org/10.1016/s0737 -0806(97)80030-5.

Appelmelk, B. J., Y. Q. An, M. Geerts, B. G. Thijs, H. A. Deboer, D. M. McClaren, J. de Graaff, and J. H. Nuijens. 1994. Lactoferrin is a lipid A-binding protein. Infect. Immun. 62:2628-2632. https:// doi.org/10.1128/IAI.62.6.2628-2632.1994.

Arqués, J. L., E. Rodríguez, S. Langa, J. M. Landete, and M. Medina. 2015. Antimicrobial activity of lactic acid bacteria in dairy products and gut: Effect on pathogens. BioMed Research International. 584183. https://doi.org/10.1155/2015/584183.

Aspri, M., D. Bozoudi, D. Tsaltas, C. Hill, and P. Papademas. 2017a. Raw donkey milk as a source of Enterococcus diversity: Assessment of their technological properties and safety characteristics. Food Control 73:81-90. https://doi.org/10.1016/j.foodcont.2016.05.022. 
Aspri, M., N. Economou, and P. Papademas. 2017b. Donkey milk: An overview on functionality, technology, and future prospects. Food Rev. Int. 33:316-333. https://doi.org/10.1080/87559129.2016 .1175014 .

Aspri, M., P. M. O'Connor, D. Field, P. D. Cotter, P. Ross, C. Hill, and P. Papademas. 2017c. Application of bacteriocin-producing Enterococcus faecium isolated from donkey milk, in the bio-control of Listeria monocytogenes in fresh whey cheese. Int. Dairy J. 73:19. https://doi.org/10.1016/j.idairyj.2017.04.008.

Boix-Amorós, A., M. C. Collado, and A. Mira. 2016. Relationship between milk microbiota, bacterial load, macronutrients, and human cells during lactation. Front. Microbiol. 7:492. https://doi.org/10 .3389/fmicb.2016.00492.

Bokulich, N. A., and D. A. Mills. 2013. Facility-specific 'house' microbiome drives microbial landscapes of artisan cheesemaking plants. Appl. Environ. Microbiol. 79:5214-5223. https://doi.org/10.1128/ AEM.00934-13.

Bolger, A. M., M. Lohse, and B. Usadel. 2014. Trimmomatic: A flexible trimmer for Illumina sequence data. Bioinformatics 30:21142120. https://doi.org/10.1093/bioinformatics/btu170.

Bolyen, E., J. R. Rideout, M. R. Dillon, N. A. Bokulich, C. C. Abnet, G. A. Al-Ghalith, H. Alexander, E. J. Alm, M. Arumugam, F. Asnicar, Y. Bai, J. E. Bisanz, K. Bittinger, A. Brejnrod, C. J. Brislawn, C. T. Brown, B. J. Callahan, A. M. Caraballo-Rodríguez, J. Chase, E. K. Cope, R. Da Silva, C. Diener, P. C. Dorrestein, G. M. Douglas, D. M. Durall, C. Duvallet, C. F. Edwardson, M. Ernst, M. Estaki, J. Fouquier, J. M. Gauglitz, S. M. Gibbons, D. L. Gibson, A. Gonzalez, K. Gorlick, J. Guo, B. Hillmann, S. Holmes, H. Holste, C. Huttenhower, G. A. Huttley, S. Janssen, A. K. Jarmusch, L. Jiang, B. D. Kaehler, K. B. Kang, C. R. Keefe, P. Keim, S. T. Kelley, D. Knights, I. Koester, T. Kosciolek, J. Kreps, M. G. I. Langille, J. Lee, R. Ley, Y. X. Liu, E. Loftfield, C. Lozupone, M.. Maher, C. Marotz, B. D. Martin, D. McDonald, L. J. McIver, A. V. Melnik, J. L. Metcalf, S. C. Morgan, J. T. Morton, A. T. Naimey, J. A. Navas-Molina, L. F. Nothias, S. B. Orchanian, T. Pearson, S. L. Peoples, D. Petras, M. L. Preuss, E. Pruesse, L. B. Rasmussen, A. Rivers, M. S. Robeson, P. Rosenthal, N. Segata, M. Shaffer, A. Shiffer, R. Sinha, S. J. Song, J. R. Spear, A. D. Swafford, L. R. Thompson, P. J. Torres, P. Trinh, A. Tripathi, P. J. Turnbaugh, S. Ul-Hasan, J. J. J. van der Hooft, F. Vargas, Y. Vázquez-Baeza, E. Vogtmann, M. von Hippel, W. Walters, Y. Wan, M. Wang, J. Warren, K. C. Weber, C. H. D. Williamson, A. D. Willis, Z. Z. Xu, J. R. Zaneveld, Y. Zhang, Q. Zhu, R. Knight, and J. G. Caporaso. 2019. Reproducible, interactive, scalable and extensible microbiome data science using QIIME 2. Nat. Biotechnol. https://doi.org/10.1038/s41587-019-0209-9.

Bonsaglia, E. C., M. S. Gomes, I. F. Canisso, Z. Zhou, S. F. Lima, V. L. Rall, G. Oikonomou, R. C. Bicalho, and F. S. Lima. 2017. Milk microbiome and bacterial load following dry cow therapy without antibiotics in dairy cows with healthy mammary gland. Sci. Rep. 7:8067. https://doi.org/10.1038/s41598-017-08790-5.

Brumini, D., A. Criscione, S. Bordonaro, G. E. Vegarud, and D. Marletta. 2016. Whey proteins and their antimicrobial properties in donkey milk: A brief review. Dairy Sci. Technol. 96:1-14. https:// doi.org/10.1007/s13594-015-0246-1.

Brumini, D., C. B. Furlund, I. Comi, T. G. Devold, D. Marletta, G. E. Vegarud, and C. M. Jonassen. 2013. Antiviral activity of donkey milk protein fractions on echovirus type 5. Int. Dairy J. 28:109 111. https://doi.org/10.1016/j.idairyj.2012.08.010.

Cabrera-Rubio, R., M. C. Collado, K. Laitinen, S. Salminen, E. Isolauri, and A. Mira. 2012. The human milk microbiome changes over lactation and is shaped by maternal weight and mode of delivery. Am. J. Clin. Nutr. 96:544-551. https://doi.org/10.3945/ajcn.112 .037382 .

Callahan, B. J., P. J. McMurdie, M. J. Rosen, A. W. Han, A. J. A. Johnson, and S. P. Holmes. 2016. DADA2: High-resolution sample inference from Illumina amplicon data. Nat. Methods 13:581-583. https://doi.org/10.1038/nmeth.3869.

Cavallarin, L., M. Giribaldi, M. D. Soto-Del Rio, E. Valle, G. Barbarino, M. S. Gennero, and T. Civera. 2015. A survey on the milk chemical and microbiological quality in dairy donkey farms located in NorthWestern Italy. Food Control 50:230-235. https://doi.org/ 10.1016/j.foodcont.2014.08.019.

Chiavari, C., F. Coloretti, M. Nanni, E. Sorrentino, and L. Grazia. 2005. Use of donkey's milk for a fermented beverage with lactobacilli. Lait 85:481-490. https://doi.org/10.1051/lait:2005031.

Colavita, G., C. Amadoro, F. Rossi, F. Fantuz, and E. Salimei. 2016. Hygienic characteristics and microbiological hazard identification in horse and donkey raw milk (Caratteristiche igienico-sanitarie ed identificazione dei rischi microbiologici nel latte di cavalla e di asina). Vet. Ital. 52:21-29. https://doi.org/10.12834/VetIt.180.545.1.

Conte, F. M. Foti, M. Malvisi, C. Giacopello, and R. Piccinini. 2012 Valutazione dell'azione antibatterica del lisozima del latte d'asina. Considerazioni igienico - Sanitarie. Large Anim. Rev. 18:13-16.

Conte, F., M. L. Scatassa, M. Todaro, and M. Barreca. 2005. Observations on some composition, hygiene, and safety parameters of donkey's milk. Ind. Aliment. 44:1265-1272, 1278.

Coppola, R., E. Salimei, M. Succi, E. Sorrentino, M. Nanni, P. Ranieri, R. Belli Blanes, and L. Grazia. 2002. Behaviour of Lactobacillus rhamnosus strains in ass's milk. Ann. Microbiol. 52:55-60.

Cosentino, C. C. Labella, H. S. Elshafie, I. Camele, M. Musto, R. Paolino, C. D'Adamo, and P. Freschi. 2016. Effects of different heat treatments on lysozyme quantity and antimicrobial activity of jenny milk. J. Dairy Sci. 99:5173-5179. https://doi.org/10.3168/ jds.2015-10702.

D'Auria, E., M. Mandelli, P. Ballista, F. Di Dio, and M. Giovannini. 2011. Growth impairment and nutritional deficiencies in a cow's milk-allergic infant fed by unmodified donkey's milk. Case Rep. Pediatr. 1-4. https://doi.org/10.1155/2011/103825.

De Filippis, F., E. Parente, and D. Ercolini. 2018. Recent past, present, and future of the food microbiome. Annu. Rev. Food Sci. Technol. 9:589-608. https://doi.org/10.1146/annurev-food-030117 -012312 .

DeSantis, T. Z., P. Hugenholtz, N. Larsen, M. Rojas, E. L. Brodie, K. Keller, T. Huber, D. Dalevi, P. Hu, and G. L. Andersen. 2006. Greengenes, a chimera-checked 16S rRNA gene database and workbench compatible with ARB. Appl. Environ. Microbiol. 72:5069-5072. https://doi.org/10.1128/AEM.03006-05.

Doyle, C. J., D. Gleeson, P. W. O'Toole, and P. D. Cotter. 2016. Impacts of seasonal housing and teat preparation on raw milk microbiota: A high-throughput sequencing study. Appl. Environ. Microbiol. 83:e02694-16. https://doi.org/10.1128/AEM.02694-16.

Ellison, R. T. 3rd, and T. J. Giehl. 1991. Killing of gram-negative bacteria by lactoferrin and lysozyme. J. Clin. Invest. 88:1080-1091. https://doi.org/10.1172/JCI115407.

Esteban-Blanco, C., B. Gutiérrez-Gil, F. Puente-Sánchez, H. Marina, J. Tamames, A. Acedo, and J. J. Arranz. 2020. Microbiota characterization of sheep milk and its association with somatic cell count using 16s rRNA gene sequencing. J. Anim. Breed. Genet. 137:73-83. https://doi.org/10.1111/jbg.12446.

European Union. 1998. Council Directive 98/58/EC of 20 July 1998 concerning the protection of animals kept for farming purposes Off. J. L 221(08), p. 08.

European Union. 2004. Regulation no. 853/2004 of the European Parliament and of the Council of 29 April 2004 laying down specific rules for food of animal origin. Off. J. Eur. Union L 226, pp. 22-82.

Falentin, H., L. Rault, A. Nicolas, D. S. Bouchard, J. Lassalas, P. Lamberton, J. M. Aubry, P. G. Marnet, Y. Le Loir, and S. Even. 2016. Bovine teat microbiome analysis revealed reduced alpha diversity and significant changes in taxonomic profiles in quarters with a history of mastitis. Front. Microbiol. 7:480. https://doi.org/ 10.3389/fmicb.2016.00480.

Guo, H. Y., K. Pang, X. Y. Zhang, L. Zhao, S. W. Chen, M. L. Dong, and F. Z. Ren. 2007. Composition, physiochemical properties, nitrogen fraction distribution, and amino acid profile of donkey milk. J. Dairy Sci. 90:1635-1643. https://doi.org/10.3168/jds.2006-600.

Hunt, K. M., J. A. Foster, L. J. Forney, U. M. Schutte, D. L. Beck, Z. Abdo, L. K. Fox, J. E. Williams, M. K. McGuire, and M. A. McGuire. 2011. Characterization of the diversity and temporal stability of bacterial communities in human milk. PLoS One 6:e21313. https://doi.org/10.1371/journal.pone.0021313. 
ISO. 1999. ISO 6888-1(1999). Microbiology of food and animal feeding stuffs. Horizontal method for the enumeration of coagulasepositive staphylococci (Staphylococcus aureus and other species). Part 1: Technique using Baird-Parker agar medium. International Organization for Standardization, Geneva, Switzerland.

ISO. 2001. ISO 16649-2:2001. Microbiology of food and animal feeding stuffs - Horizontal method for the enumeration of beta-glucuronidase-positive Escherichia coli - Part 2: Colony-count technique at 44 degrees $\mathrm{C}$ using 5-bromo-4-chloro-3-indolyl beta-D-glucuronide. International Organization for Standardization, Geneva, Switzerland.

ISO. 2004a. ISO 21528-2:2004. Microbiology of food and animal feeding stuffs - Horizontal methods for the detection and enumeration of Enterobacteriaceae - Part 2: Colony-count method. International Organization for Standardization, Geneva, Switzerland.

ISO. 2004b. ISO 7932:2004. Microbiology of food and animal feeding stuffs - Horizontal method for the enumeration of presumptive Bacillus cereus - Colony-count technique at 30 degrees C. International Organization for Standardization, Geneva, Switzerland.

ISO. 2008. ISO 488:2008 (IDF 105:2008). Milk-determination of fat content-Gerber butyrometers. International Organization for Standardization, Geneva, Switzerland.

ISO. 2014. ISO 8968-1:2014 (IDF 20-1:2014) Milk and milk products: Determination of nitrogen content-Part 1: Kjeldahl principle and crude protein calculation. International Organization for Standardization, Geneva, Switzerland.

ISO. 2010. ISO 6731:2010 (IDF 21:2010). Milk, cream and evaporated milk-Determination of total solids content (Reference method). International Organization for Standardization, Geneva, Switzerland.

ISO. 2013. ISO 4833-2:2013. Microbiology of food and animal feeding stuffs-Horizontal method for the enumeration of microorganisms - Colony-count technique at 30 degrees C by the surface plating technique. International Organization for Standardization, Geneva, Switzerland.

ISO. 2017. ISO 11290-1:2017. Microbiology of the food chain-Horizontal method for the detection and enumeration of Listeria monocytogenes and of Listeria spp. Part 1: Detection method. International Organization for Standardization, Geneva, Switzerland.

Jahani, S., A. Shakiba, and L. Jahani. 2015. The antimicrobial effect of lactoferrin on gram-negative and gram-positive bacteria. Int. J. Infect. 2:e27954. https://doi.org/10.17795/iji27594.

Jirillo, F., E. Jirillo, and T. Magrone. 2010. Donkey's and goat's milk consumption and benefits to human health with special reference to the inflammatory status. Curr. Pharm. Des. 16:859-863. https: //doi.org/10.2174/138161210790883688.

Jirillo, F., and T. Magrone. 2014. Anti-inflammatory and antiallergic properties of donkey's and goat's milk. Endocr. Metab. Immune Disord. Targets 14:27-37. https://doi.org/10.2174/ 1871530314666140121143747.

Jost, T., C. Lacroix, C. Braegger, and C. Chassard. 2015. Impact of human milk bacteria and oligosaccharides on neonatal gut microbiota establishment and gut health. Nutr. Rev. 73:426-437. https: //doi.org/10.1093/nutrit/nuu016.

Kamilari, E., D. A. Anagnostopoulos, P. Papademas, A. Kamilaris, and D. Tsaltas. 2020. Characterizing Halloumi cheese's bacterial communities through metagenomic analysis. Lebensm. Wiss. Technol. 126:109298. https://doi.org/10.1016/j.lwt.2020.109298.

Kamilari, E., M. Tomazou, A. Antoniades, and D. Tsaltas. 2019. High throughput sequencing technologies as a new toolbox for deep analysis, characterization and potentially authentication of protection designation of origin cheeses? Int. J. Food Sci. 2019:5837301. https://doi.org/10.1155/2019/5837301.

Karaś, M. A., A. Turska-Szewczuk, D. Trapska, and T. UrbanikSypniewska. 2015. Growth and survival of Mesorhizobium loti inside acanthamoeba enhanced its ability to develop more nodules on Lotus corniculatus. Microb. Ecol. 70:566-575. https://doi.org/ 10.1007/s00248-015-0587-6.

Katoh, K., and D. M. Standley. 2013. MAFFT multiple sequence alignment software version 7: Improvements in performance and usability. Mol. Biol. Evol. 30:772-780. https://doi.org/10.1093/ molbev/mst010.

Kelley, S. T., U. Theisen, L. T. Angenent, A. St. Amand, and N. R. Pace. 2004. Molecular analysis of shower curtain biofilm microbes. Appl. Environ. Microbiol. 70:4187-4192. https://doi.org/10.1128/ AEM.70.7.4187-4192.2004.

Khan, J. A., P. Kumar, M. Paramasivam, R. S. Yadav, M. S. Sahani, S. Sharma, A. Srinivasan, and T. P. Singh. 2001. Camel lactoferrin, a transferrin-cum-lactoferrin: Crystal structure of camel apolactoferrin at $2.6 \AA$ resolution and structural basis of its dual role. J. Mol. Biol. 309:751-761. https://doi.org/10.1006/jmbi.2001.4692.

Klindworth, A., Pruesse, E. Schweer, T. Peplies, C. Quast, H. Horn, and F. O. Glöckner. 2013. Evaluation of general 16S ribosomal RNA gene PCR primers for classical and next-generation sequencing-based diversity studies. Nucleic Acids Res. 41:e1. https://doi .org/10.1093/nar/gks808.

Koutb, M. 2016. Antimicrobial activity of donkey milk against dermatomycotic fungi and foodborne bacteria. Int. J. Biomed. Mater. Res. 4:11-17. https://doi.org/10.11648/j.ijbmr.20160403.11.

Krziwon, C., U. Zähringer, K. Kawahara, B. Weidemann, S. Kusumoto, E. T. Rietschel, H. D. Flad, and A. J. Ulmer. 1995. Glycosphingolipids from Sphingomonas paucimobilis induce monokine production in human mononuclear cells. Infect. Immun. 63:2899-2905. https://doi.org/10.1128/IAI.63.8.2899-2905.1995.

Kuehn, J. S., P. J. Gorden, D. Munro, R. Rong, Q. Dong, P. J. Plummer, C. Wang, and G. J. Phillips. 2013. Bacterial community profiling of milk samples as a means to understand culture-negative bovine clinical mastitis. PLoS One 8:e61959. https://doi.org/10 .1371/journal.pone.0061959.

Kumar, H., E. du Toit, A. Kulkarni, J. Aakko, K. M. Linderborg, Y. Zhang, M. P. Nicol, E. Isolauri, B. Yang, M. C. Collado, and S. Salminen. 2016. Distinct patterns in human milk microbiota and fatty acid profiles across specific geographic locations. Front. Microbiol. 7:1619. https://doi.org/10.3389/fmicb.2016.01619.

Labella, C., F. Lelario, S. A. Bufo, M. Musto, P. Freschi, and C. Cosentino. 2016. Optimization and validation of a chromatografic method for quantification of lysozyme in jenny milk. J. Food Nutr. Res. 55:263-269.

Li, S. W., K. Watanabe, C. C. Hsu, S. H. Chao, Z. H. Yang, Y. J. Lin, C. C. Chen, Y. M. Cao, H. C. Huang, C. H. Chang, and Y. C. Tsai. 2017. Bacterial composition and diversity in breast milk samples from mothers living in Taiwan and Mainland China. Front. Microbiol. 8:965. https://doi.org/10.3389/fmicb.2017.00965.

Lima, S. F., A. G. Teixeira, F. S. Lima, E. K. Ganda, C. H. Higgins, G. Oikonomou, and R. C. Bicalho. 2017. The bovine colostrum microbiome and its association with clinical mastitis. J. Dairy Sci. 100:3031-3042. https://doi.org/10.3168/jds.2016-11604.

Lindström, K., M. Murwira, A. Willems, and N. Altier. 2010. The biodiversity of beneficial microbe-host mutualism: The case of rhizobia. Res. Microbiol. 161:453-463. https://doi.org/10.1016/j.resmic 2010.05.005.

Macaluso, G., G. Fiorenza, R. Gaglio, I. Mancuso, and M. L. Scatassa. 2016. In vitro evaluation of bacteriocin-like inhibitory substances produced by lactic acid bacteria isolated during traditional Sicilian cheese making. Ital. J. Food Saf. 5:5503. https://doi.org/10.4081/ ijfs. 2016.5503.

Malissiova, E., G. Arsenos, P. Papademas, D. Fletouris, A. Manouras, M. Aspri, A. Nikolopoulou, A. Giannopoulou, and I. S. Arvanitoyannis. 2016. Assessment of donkey milk chemical, microbiological and sensory attributes in Greece and Cyprus. Int. J. Dairy Technol. 69:143-146. https://doi.org/10.1111/1471-0307.12245.

Mao, X., J. Gu, Y. Sun, S. Xu, X. Zhang, H. Yang, and F. Ren. 2009. Anti-proliferative and anti-tumour effect of active components in donkey milk on A549 human lung cancer cells. Int. Dairy J. 19:703-708. https://doi.org/10.1016/j.idairyj.2009.05.007.

McInnis, E. A., K. M. Kalanetra, D. A. Mills, and E. A. Maga. 2015. Analysis of raw goat milk microbiota: Impact of stage of lactation and lysozyme on microbial diversity. Food Microbiol. 46:121-131. https://doi.org/10.1016/j.fm.2014.07.021.

Mottola, A., L. Alberghini, V. Giaccone, P. Marchetti, G. Tantillo, and A. Di Pinto. 2018. Microbiological safety and quality of Ital- 
ian donkey milk. J. Food Saf. 38:e12444. https://doi.org/10.1111/ jfs.12444.

Murphy, K., D. Curley, T. F. O'Callaghan, C. A. O'Shea, E. M. Dempsey, P. W. O'Toole, R. P. Ross, C. A. Ryan, and C. Stanton. 2017. The composition of human milk and infant faecal microbiota over the first three months of life: A pilot study. Sci. Rep. 7:40597. https://doi.org/10.1038/srep40597.

Neviani, E., D. Carminati, M. Veaux, J. Hermier, and G. Giraffa. 1991. Characterization of Lactobacillus helveticus strains resistant to lysozyme. Lait 71:65-73. https://doi.org/10.1051/lait:199115.

Nishiyama, M., K. Senoo, H. Wada, and S. Matsumoto. 1992. Identification of soil micro-habitats for growth, death and survival of a bacterium, $\gamma-1,2,3,4,5,6$-hexachlorocyclohexane-assimilating Sphingomonas paucimobilis, by fractionation of soil. FEMS Microbiol. Lett. 10:145-150. https://doi.org/10.1111/j.1574-6941.1992 .tb01650.x.

Ochoa, T. J., and T. G. Cleary. 2009. Effect of lactoferrin on enteric pathogens. Biochimie 91:30-34. https://doi.org/10.1016/j.biochi 2008.04.006

Oikonomou, G., M. F. Addis, C. Chassard, M. E. F. Nader-Macias, I. Grant, C. Delbès, C. I. Bogni, Y. Le Loir, and S. Even. 2020. Milk microbiota: What are we exactly talking about? Front. Microbiol. 11:60. https://doi.org/10.3389/fmicb.2020.00060.

Papademas, P., M. Aspri, M. Mariou, S. E. Dowd, M. Kazou, and E. Tsakalidou. 2019. Conventional and omics approaches shed light on Halitzia cheese, a long-forgotten white-brined cheese from Cyprus. Int. Dairy J. 98:72-83. https://doi.org/10.1016/j.idairyj .2019.06.010

Pilla, R., V. Daprà, A. Zecconi, and R. Piccinini. 2010. Hygienic and health characteristics of donkey milk during a followup study. J. Dairy Res. 77:392-397. https://doi.org/10.1017/ S0022029910000221.

Porcellato, D., M. Aspholm, S. B. Skeie, M. Monshaugen, J. Brendehaug, and H. Mellegård. 2018. Microbial diversity of consumption milk during processing and storage. Int. J. Food Microbiol. 266:21-30. https://doi.org/10.1016/j.ijfoodmicro.2017.11.004.

Quigley, L., R. McCarthy, O. O'Sullivan, T. P. Beresford, G. F. Fitzgerald, R. P. Ross, C. Stanton, and P. D. Cotter. 2013a. The microbial content of raw and pasteurized cow milk as determined by molecular approaches. J. Dairy Sci. 96:4928-4937. https://doi .org/10.3168/jds.2013-6688.

Quigley, L., O. O'Sullivan, C. Stanton, T. P. Beresford, R. P. Ross, G. F. Fitzgerald, and P. D. Cotter. 2013b. The complex microbiota of raw milk. FEMS Microbiol. Rev. 37:664-698. https://doi.org/10 $.1111 / 1574-6976.12030$

Rodriguez, J. M. 2014. The origin of human milk bacteria: Is there a bacterial entero-mammary pathway during late pregnancy and lactation? Adv. Nutr. 5:779-784. https://doi.org/10.3945/an.114 .007229 .

Russo, P., D. Fiocco, M. Albenzio, G. Spano, and V. Capozzi. 2020. Microbial populations of fresh and cold stored donkey milk by high-throughput sequencing provide indication for a correct management of this high-value product. Appl. Sci. (Basel) 10:2314. https://doi.org/10.3390/app10072314.

Salimei, E., and F. Fantuz. 2012. Equid milk for human consumption. Int. Dairy J. 24:130-142. https://doi.org/10.1016/j.idairyj.2011.11 .008 .

Salimei, E., F. Fantuz, R. Coppola, B. Chiofalo, P. Polidori, and G. Varisco. 2004. Composition and characteristics of ass's milk. Anim. Res. 53:67-78. https://doi.org/10.1051/animres:2003049.

Šarić, L. Ć., B. M. Šaríc, A. I. Mandíc, A. M. Torbica, L. M. Tomić, D. D. Cvetković, and Đ. G. Okanović. 2012. Antibacterial properties of domestic Balkan donkeys' milk. Int. Dairy J. 25:142-146. https: //doi.org/10.1016/j.idairyj.2012.03.007.

Sarno, E., A. M. L. Santoro, R. Di Palo, and N. Costanzo. 2012. Microbiological quality of raw donkey milk from Campania region. Ital. J. Anim. Sci. 11:e49. https://doi.org/10.4081/ijas.2012.e49.

Soto Del Rio, M., A. Dalmasso, T. Civera, and M. T. Bottero. 2017. Characterization of bacterial communities of donkey milk by highthroughput sequencing. Int. J. Food Microbiol. 251:67-72. https:/ /doi.org/10.1016/j.ijfoodmicro.2017.03.023.
Souroullas, K., M. Aspri, and P. Papademas. 2018. Donkey milk as a supplement in infant formula: Benefits and technological challenges. Food Res. Int. 109:416-425. https://doi.org/10.1016/j.foodres 2018.04.051.

Superti, F., A. Pietrantoni, A. M. Di Biase, C. Longhi, P. Valenti, and A. Tinari. 2005. Inv-mediated apoptosis of epithelial cells infected with enteropathogenic Yersinia: A protective effect of lactoferrin. Res. Microbiol. 156:728-737. https://doi.org/10.1016/j.resmic 2005.02.007.

Tidona, F., C. Sekse, A. Criscione, M. Jacobsen, S. Bordonaro, D. Marletta, and G. E. Vegarud. 2011. Antimicrobial effect of donkeys' milk digested in vitro with human gastrointestinal enzymes. Int. Dairy J. 21:158-165. https://doi.org/10.1016/j.idairyj.2010.10 .008 .

Treven, P., A. Mahnič, M. Rupnik, M. Golob, T. Pirš, B. B. Matijašić and P. M. Lorbeg. 2019. Evaluation of human milk microbiota by $16 \mathrm{~S}$ rRNA gene next-generation sequencing (NGS) and cultivation/MALDI-TOF mass spectrometry identification. Front. Microbiol. 10:2612. https://doi.org/10.3389/fmicb.2019.02612.

Urbaniak, C., J. Cummins, M. Brackstone, J. M. Macklaim, G. B. Gloor, C. K. Baban, L. Scott, D. M. O'Hanlon, J. P. Burton, K. P. Francis, M. Tangney, and G. Reid. 2014. Microbiota of human breast tissue. Appl. Environ. Microbiol. 80:3007-3014. https://doi .org/10.1128/AEM.00242-14.

Vincenzetti, S., P. Polidori, P. Mariani, N. Cammertoni, F. Fantuz, and A. Vita. 2008. Donkey's milk protein fractions characterization. Food Chem. 106:640-649. https://doi.org/10.1016/j .foodchem.2007.06.026.

Ward, P. P., and O. M. Conneely. 2004. Lactoferrin: Role in iron homeostasis and host defense against microbial infection. Biometals 17:203-208. https://doi.org/10.1023/B:BIOM.0000027693.60932 .26

Williams, J. E., J. M. Carrothers, K. A. Lackey, N. F. Beatty, S. L. Brooker, H. K. Peterson, K. M. Steinkamp, M. A. York, B. Shafii, W. J. Price, M. A. McGuire, and M. K. McGuire. 2019. Strong multivariate relations exist among milk, oral, and fecal microbiomes in mother-infant dyads during the first six months postpartum. J. Nutr. 149:902-914. https://doi.org/10.1093/jn/nxy299.

Williams, J. E., J. M. Carrothers, K. A. Lackey, N. F. Beatty, M. A. York, S. L. Brooker, B. Shafii, W. J. Price, M. L. Settles, M A. McGuire, and M. K. McGuire. 2017. Human milk microbial community structure is relatively stable and related to variations in macronutrient and micronutrient intakes in healthy lactating women. J. Nutr. 147:1739-1748. https://doi.org/10.3945/jn.117 .248864 .

Yvon, S., M. Olier, M. Leveque, G. Jard, H. Tormo, D. A. HaimoudLekhal, M. Peter, and H. Eutamène. 2018. Donkey milk consumption exerts anti-inflammatory properties by normalizing antimicrobial peptides levels in Paneth's cells in a model of ileitis in mice. Eur. J. Nutr. 57:155-166. https://doi.org/10.1007/s00394 $-016-1304-z$

Zhang, D., J. Palmer, K. H. Teh, P. Biggs, and S. Flint. 2019. 16S rDNA high-throughput sequencing and MALDI-TOF MS are complementary when studying psychrotrophic bacterial diversity of raw cows' milk. Int. Dairy J. 97:86-91. https://doi.org/10.1016/ j.idairyj.2019.06.001.

Zhang, X. Y., L. Zhao, L. Jiang, M. L. Dong, and F. Z. Ren. 2008. The antimicrobial activity of donkey milk and its microflora changes during storage. Food Control 19:1191-1195. https://doi.org/10 .1016/j.foodcont.2008.01.00-5.

\section{ORCIDS}

P. Papademas () https://orcid.org/0000-0003-0284-2247

E. Kamilari @ https://orcid.org/0000-0002-2473-9729

M. Aspri ㄴ https://orcid.org/0000-0001-5876-3922

D. A. Anagnostopoulos @ https://orcid.org/0000-0001-9867-2291

P. Mousikos (ㄴ https://orcid.org/0000-0002-5633-1963

A. Kamilaris @ https://orcid.org/0000-0002-8484-4256

D. Tsaltas @ https://orcid.org/0000-0001-6546-3602 